\title{
ANALISIS FAKTOR YANG MEMPENGARUHI KETIDAKLENGKAPAN KODE EXTERNAL CAUSE PASIEN ORTHOPEDI PADA DOKUMEN REKAM MEDIS RAWAT INAP DI RSUP.H. ADAM MALIK TAHUN 2018
}

\author{
1. Fitriyani; ${ }^{2 .}$ Susiriani \\ 1. Dosen APIKES Imelda. Jalan Bilal Nomor 52 Medan, ${ }^{2}$ Alumni APIKES Imelda
}

E-mail : fitriyanilubis38@gmail.com

\begin{abstract}
ABSTRAK
External cause (penyebab luar) merupakan klasifikasi tambahan yang mengklasifikasikan kemungkinan kejadian, lingkungan dan keadaan sebagai penyebab cedera, keracunan dan efek samping lainnya. Tujuan penelitian ini adalah untuk menganalisis faktor yang mempengaruhi ketidaklengkapan kode external cause pasien orthopedi pada rekam medis rawat inap di RSUP.H.Adam Malik. Jenis penelitian ini menggunakan deskriptif kuantitatif. Metode penelitian yang digunakan adalah metode observasi dengan pendekatan cross sectional. Tempat penelitian dilakukan peneliti yaitu Rumah Sakit Umum Pusat Haji Adam Malik Medan. Populasi penelitian adalah seluruh petugas rekam medis bagian koding sebanyak 16 petugas dengan mengunakan teknik total sampling dengan metodologi penelitian menggunakan metode deskriptif kuantitatif. Instrumen dalam penelitian ini menggunakan kuesioner. Dari hasil yang diperoleh dari penelitian yaitu 16 responden ada hubungan antara pengalaman kerja, pengetahuan dan sikap petugas rekam medis dengan ketidaklengkapan kode external cause pasien orthopedic di Rumah Sakit Umum Pusat Haji Adam Malik. Berdasarkan hal tersebut disarankan untuk memberian evaluasi skala berkala tentang kode external cause.
\end{abstract}

Kata Kunci : Karakteristik, Pengetahuan, Sikap, Kode External Cause

\begin{abstract}
External cause is an additional classification that classifies the possibility of occurrence, environment and circumstances as a cause of injury, poisoning and other side effects. The purpose of this study was to analyze the factors that influence the incompleteness of the external code causing orthopedic patients in inpatient medical records at RSUP.H.Adam Malik. This type of research uses quantitative descriptive. The research method used is the observation method with a cross sectional approach. The research site was conducted by researchers, namely the RSUP. H. Adam Malik Medan. The population of the study was all the officers of the medical record coding section as many as 16 officers using the total sampling technique with the research methodology using quantitative descriptive method. The instrument in this study uses a questionnaire. From the results obtained from the study, 16 respondents had a relationship between work experience, knowledge and attitudes of medical record officers with incomplete external cause code for orthopedic patients at RSUP. H. Adam Malik Medan. Based on this, it is recommended to provide a periodic evaluation of the external cause code.
\end{abstract}

Keywords : Characteristics, Knowledge, Attitude, External Cause Code 


\section{PENDAHULUAN}

Rekam medis merupakan berkas yang berisikan catatan dan dokumen tentang identitas pasien, pemeriksaaan, pengobatan, tindakan, dan pelayanan lain yang telah diberikan kepada pasien, rekam medis harus dibuat secara tertulis, lengkap dan jelas (Hatta, 2012).

Sistem penyelenggaraan rekam medis salah satunya yaitu pengolahan data rekam medis, kegiatan pengolahan data pada penyelenggaraan rekam medis salah satunya yang dilakukan yaitu koding (pemberian kode untuk klasifikasi penyakit) (Dirjen Binyamed, 2006).

Klasifikasi penyakit merupakan kategori atau pengelompokan, tempat penyakit, cedera, kondisi dan prosedur dimasukkan sesuai dengan kriteria yang telah ditentukan. Pengelompokan istilah yang sama membedakan klasifikasi statistik dari nomenklatur. Nomenklatur memerlukan nama tersendiri untuk setiap penyakit atau prosedur (Erkadius, 2010).

Klasifikasi penyakit dapat dilakukan berdasarkan penyebabnya, patologi penyakit, organ yang terserang, cara pengobatannya, cara penyebarannya, cara masuk atau keluarnya penyakit dan faktor keterpaparan atau kepekaannya. Untuk mempermudah proses dalam pengklasifikasian penyakit mengacu pada ICD-10 (WHO, 2010).

Kodefikasi (coding) merupakan prosedur pemberian kode dengan menggunakan huruf dan angka. Kodefikasi untuk indeks alphabet penyakit dan bentuk cedera, penyebab luar cedera, tabel obat dan zat kimia. Pengkodean diagnosis yang tepat akan menghasilkan data yang akurat dan berkualitas (Hatta, 2014).

Pengkodean diagnosis untuk kasus kecelakaan harus diikuti pengkodean penyebab luar (external cause) untuk menggambarkan sifat kondisi dan keadaan yang menimbulkannya. Pengkodean external cause dilakukan secara terpisah pada Bab XX Penyebab Luar Morbiditas dan Mortalitas (V01-Y98). Kode kasus kecelakaan dikatakan lengkap apabila terdapat kode diagnosa cedera dan kode external cause penyebab kecelakaan (Sartianingrum M, 2014).

Kode external cause (penyebab luar) merupakan kode yang digunakan dalam mengklasifikasi penyebab luar terjadinya suatu penyakit, baik yang diakibatkan karena kasus kecelakaan, cedera, pendarahan, keracunan, bencana alam, maupun penyebab lainnya (WHO, 2010).

Klasifikasi kode external cause untuk menentukan kode external cause harus lengkap sampai karakter kelima, meliputi kategori ketiga yang menunjukkan bagaimana kecelakaan terjadi, karakter keempat yang menunjukan lokasi terjadinya kecelakaan, dan karakter kelima yang menunjukkan aktivitas pasien saat terjadinya kecelakaan (WHO, 2010)

ICECI (international Classification of External Cause of Injury) Klasifikasi Internasional Eksternal Penyebab Cedera adalah sistem klasifikasi untuk memungkinkan deskripsi sistematis tentang bagaimana cedera terjadi. Ini dirancang khusus untuk membantu pencegahan cedera. ICECI pada awalnya dirancang untuk digunakan dalam pengaturan dimana informasi dicatat dengan cara yang memungkinkan pelaporan statistik.

Selain itu dalam ICECI (International Classification of External Cause of Injury) menjelaskan bahwa tujuan pengkodean penyebab luar adalah membantu para peneliti dan praktisi untuk melakukan pencegahan dengan menggambarkan, mengukur, dan memantau terjadinya kecelakaan dan untuk menyelidiki keadaan waktu kejadian dengan menggunakan klasifikasi yang disepakati secara internasional (ICECI, 2017).

Berdasarkan uraian tersebut, maka peneliti tertarik untuk melakukan penelitian dengan judul "Analisis Faktor Yang Mempengaruhi Ketidaklengkapan Kode External Cause Pasien Orthopedi Pada Rekam Medis Rawat Inap di RSUP.H. Adam Malik Tahun 2018”.

\section{Rumusan Masalah}

Berdasarkan latar belakang yang telah diuraikan diatas maka rumusan masalah dalam penelitian ini adalah faktor apasaja 
yang memengaruhi ketidaklengkapan kode external cause pasien Orthopedi pada rekam medis rawat inap di RSUP.H Adam Malik Tahun 2018 ?

\section{Tujuan Penelitian}

Adapun tujuan dari peneliti ini adalah untuk menganalisis faktor yang memengaruhi ketidaklengkapan kode external cause pasien Orthopedi pada rekam medis rawat inap di RSUP.H Adam Malik Tahun 2018.

\section{Manfaat Penelitian}

1. Bagi Rumah Sakit

Sebagai bahan masukan dalam mengelola dan menentukan kode external cause yang lengkap. Serta meningkatkan kinerja petugas rekam medis dalam pengkodean external cause.

2. Bagi Institusi Pendidikan

Dapat menambah wawasan ilmu pengetahuan bagi mahasiswa dan sebagai bahan referensi perpustakaan serta peneliti selanjutnya.

3. Bagi Peneliti

Memperluas pengetahuan tentang kode external cause pasien orthopedic serta implementasinya dilapangan.

\section{METODE}

Metode yang digunakan dalam penelitian ini adalah penelitian kuantitatif, metode penelitiannya menggunakan observasi dengan pendekatan cross sectional.

\section{Tempat Penelitian}

Tempat yang dilakukan dalam penelitian ini yaitu Rumah Sakit Umum Pusat Haji Adam Malik Medan yang beralamat di Jl. Bunga Lau No. 17 Kemenangan Tani, Medan Tuntungan. Alasan Pemilih tempat penelitian adalah karena terdapat masalah yang akan diteliti.

\section{Populasi}

Populasi adalah Keseluruhan sumber data yang diperlukan dalam suatu penelitian (Saryono, 2013). Populasi pada penelitian ini adalah jumlah seluruh petugas koding di RSUP.H.Adam Malik sebanyak 16 petugas rekam medis di RSUP.H.Adam Malik.

\section{Sampel}

Sampel adalah sebagian populasi yang cirinya diselidiki atau diukur (Sulistyaningsih, 2011). Sampel penelitian berdasarkan pendapat Arikunto (2010), bahwa apabila subjeknya kurang dari 100, lebih baik semua sehingga penelitiannya merupakan penelitian populasi. Dalam penelitian ini mengambil jumlah total sampel yaitu jumlah seluruh petugas koding di RSUP.H.Adam Malik sebanyak 16 petugas.

\section{Teknik Sampling}

Teknik sampling yang digunakan dalam penelitian ini total sampling yaitu semua populasi dijadikan sampel (Notoatmodjo, 2012).

\section{Variabel Penelitian}

Variabel merupakan ukuran atau ciri yang dimiliki oleh anggota-anggota suatu kelompok yang berbeda dengan yang dimiliki oleh kelompok lain (Saryono, 2013). Variabel Independent (bebas) adalah variabel yang mempengaruhi atau dianggap menentukan variabel terikat. Variabel Dependent (terikat) adalah variabel yang dipengaruhi. Adapun variabel dalam penelitian ini sebagai berikut :

1. Karakteristik petugas

2. Pengetahuan petugas

3. Sikap petugas

\section{Definisi Operasional}

Untuk membatasi ruang lingkup atau pengertian variabel-variabel tersebut diberi batasan atau definisi operasional (Notoatmodjo, 2012). Adapun definisi operasional pada penelitian ini sebagai berikut:

\section{Instrumen Penelitian}

Instrumen penelitian adalah alat-alat yang digunakan untuk pengumpulan data (Notoatmodjo, 2012). Maka instrumen yang digunakan dalam penelitian ini dengan menggunakan kuesioner. 


\section{Cara Pengumpulan Data}

Cara pengumpulan data pada penelitian ini adalah sebagai berikut :

1. Data Primer

Data primer merupakan data yang diperoleh secara langsung dari objek yang diteliti. Data primer diperoleh dari kuesioner yang dilakukan (Saryono, 2013).

2. Data Sekunder

Data sekunder merupakan sumber data yang tidak langsung memberikan data kepada pengumpul data, misalnya lewat orang lain atau lewat dokumen (Saryono, 2013).

\section{Pengolahan Data}

Setelah data terkumpul maka dilakukanlah pengolahan data

(Notoatmodjo, 2012), data diolah secara:

1. Editing, yaitu dengan melakukan pengecekan isian formulir (angka dan kuesioner) apakah jawaban sudah jekas, lengkap dan konsisten.

2. Coding, setelah semua kuesioner diedit atau disunting, selanjutnya dilakukan pengkodean atau coding, yakni mengubah data berbentuk kalimat atau huruf menjadi data angka atau bilangan.

3. Entry, yaitu memasukkan jawabanjawaban dari responden dalam bentuk kode (angka atau huruf) kedalam program atau software komputer.

4. Tabulasi Data, merupakan proses pengelolahan data yang dilakukan dengan cara memasukkan data kedalam tabel atau dapat penyajian data dalam bentuk tabel dan daftar untuk memasukkan dalam pengamatan dan evaluasi.

5. Cleaning, yaitu melakukan pembersihan data dengan cara memeriksa data yang telah dimasukkan apakah sesuai dengan kategori yang telah ditentukan sebelumnya.

\section{Analisis Data}

Analisis data yang digunakan yaitu analisis univariat dan analisa bivariat yang dilakukan tiap variabel dari hasil penelitian.

\section{HASIL}

Analisa Univariat

Tabel 1. Distribusi Frekuensi Petugas Rekam Medis Berdasarkan Umur di RSUP.H. Adam Malik

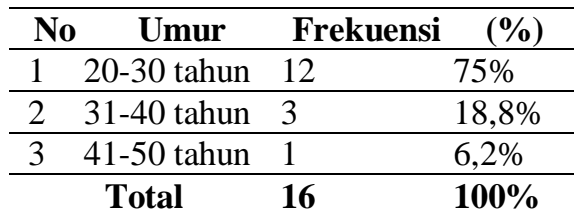

Tabel diatas menunjukan bahwa distribusi umur petugas rekam medis dari 16 responden yang telah diteliti, responden yang berumur 20-30 tahun lebih banyak yaitu sebanyak 12 responden (75\%), dibanding petugas rekam medis yang berumur 41-50 tahun yaitu sebanyak 1 responden $(6,2 \%)$.

Tabel 2. Distribusi Frekuensi Petugas Rekam Medis Berdasarkan Pendidikan Terakhir di RSUP.H.Adam Malik

\begin{tabular}{cccc}
\hline No & Pendidikan Terakhir & Frekuensi & $\mathbf{( \% )}$ \\
\hline 1 & D3 RMIK & 16 & $100 \%$ \\
\hline 2 & D3 non RMIK & - & $0 \%$ \\
\hline 3 & S1 RMIK & - & $0 \%$ \\
\hline & Total & $\mathbf{1 6}$ & $\mathbf{1 0 0 \%}$
\end{tabular}

Tabel diatas menunjukan bahwa distribusi pendidikan petugas rekam medis dari 16 responden yang diteliti, petugas rekam medis dengan latar pendidikan D3 RMIK sebanyak 16 Responden (100\%).

Tabel 3. Distribusi Frekuensi Petugas Rekam Medis Berdasarkan Pengalaman Kerja di RSUP.H. Adam Malik

\begin{tabular}{cccc}
\hline No & $\begin{array}{c}\text { Pengalaman } \\
\text { Kerja }\end{array}$ & Frekuensi & $\mathbf{( \% )}$ \\
\hline 1 & $<1-3$ tahun & 5 & $31,2 \%$ \\
\hline 2 & $<4-6$ tahun & 8 & $50 \%$ \\
\hline 3 & $<7-10$ tahun & 3 & $18,8 \%$ \\
\hline 4 & $>10$ tahun & - & $0 \%$ \\
\hline & Total & $\mathbf{1 6}$ & $\mathbf{1 0 0 \%}$
\end{tabular}

Tabel diatas menunjukan bahwa distribusi pengalaman kerja petugas rekam medis dari 16 responden yang telah diteliti, petugas rekam medis dengan pengalaman kerja 4-6 tahun lebih banyak yaitu sebanyak 8 responden $(50 \%)$. Petugas rekam medis dengan pengalaman kerja $<7-10$ tahun sebanyak 3 responden $(18,8 \%)$. 
Tabel 4. Distribusi Frekuensi Petugas Rekam Medis Berdasarkan Jenis Kelamin di RSUP.H. Adam Malik

\begin{tabular}{llcc}
\hline No & Jenis Kelamin & Frekuensi & $\mathbf{( \% )}$ \\
\hline 1 & Laki-laki & 4 & $25 \%$ \\
\hline 2 & Perempuan & 12 & $75 \%$ \\
\hline & Total & $\mathbf{1 6}$ & $\mathbf{1 0 0 \%}$ \\
\hline
\end{tabular}

Tabel diatas menunjukan bahwa distribusi jenis kelamin petugas rekam medis dari 16 responden yang telah diteliti, petugas rekam medis yang berjenis kelamin perempuan lebih banyak dari petugas rekam medis yang berjenis kelamin laki-laki. Petugas rekam medis yang berjenis kelamin perempuan sebanyak 12 responden $(75 \%)$, dan laki-laki sebanyak 4 responden $(25 \%)$.

Tabel 5. Distribusi Frekuensi Petugas Rekam Medis Berdasarkan Pelatihan Koding di RSUP.H.Adam Malik

\begin{tabular}{|c|c|c|c|}
\hline No & Pelatihan & Frekuensi & $(\%)$ \\
\hline 1 & Ada & 14 & $87,5 \%$ \\
\hline 2 & Tidak Ada & 2 & $12,5 \%$ \\
\hline & Total & 16 & $100 \%$ \\
\hline
\end{tabular}
distibusi pelatihan petugas rekam medis dari 16 responden yang telah diteliti, petugas rekam medis yang ada mengikuti pelatihan lebih banyak dari petugas rekam medis yang tidak ada mengikuti pelatihan. Petugas rekam medis yang ada mengikuti pelatihan sebanyak 14 responden $(87,5 \%)$, dan yang tidak mengikuti pelatihan sebanyak 2 responden $(12,5 \%)$.

Tabel 6. Distribusi Frekuensi Berdasarkan Pengetahuan Petugas Rekam Medis di RSUP.H. Adam Malik

\begin{tabular}{clcc}
\hline No. & Pengetahuan & Frekuensi & \% \\
\hline 1. & Baik & 10 & 62,5 \\
\hline 2. & Cukup & 6 & 37.5 \\
\hline 3. & Kurang & - & - \\
\hline & Total & $\mathbf{1 6}$ & $\mathbf{1 0 0}$ \\
\hline
\end{tabular}

Tabel diatas menunjukkan bahwa distribusi pengetahuan petugas rekam medis dari 16 responden yang diteliti, petugas rekam medis yang berpengetahuan baik lebih banyak dari petugas rekam medis yang berpengetahuan cukup. Petugas rekam medis yang berpengetahuan baik sebanyak 10 responden $(62,5 \%)$, dan petugas yang berpengetahuan cukup sebanyak 6 responden $(37,5)$.

Tabel 7. Distribusi Frekuensi Berdasarkan Sikap Petugas Rekam Medis di RSUP.H. Adam Malik

\begin{tabular}{llll}
\hline No. & Sikap & Frekuensi & Persentase $\mathbf{( \% )}$ \\
\hline 1. & Baik & 5 & 31,3 \\
\hline 2. & Cukup & 10 & 62,5 \\
\hline 3. & Kurang & 1 & 6,3 \\
\hline \multicolumn{2}{l}{ Total } & $\mathbf{1 6}$ & $\mathbf{1 0 0}$ \\
\hline
\end{tabular}

Tabel diatas menunjukan bahwa distribusi sikap petugas rekam medis dari 16 responden yang telah diteliti, petugas rekam medis yang bersikap cukup lebih banyak dari petugas yang bersikap baik. Petugas rekam medis yang bersikap cukup sebanyak 10 responden $(31,3 \%)$, dan petugas yang bersikap baik sebanyak 5 responden $(6,3 \%)$.

Tabel 8. Distribusi Frekuensi Berdasarkan Ketidaklengkapan Kode External Cause Pasien Orthopedi di RSUP.H. Adam Malik

\begin{tabular}{cccc}
\hline No. & $\begin{array}{c}\text { Kelengkapan } \\
\text { Kode External } \\
\text { Cause }\end{array}$ & Frekuensi & $\begin{array}{c}\text { Persentase } \\
(\boldsymbol{\%})\end{array}$ \\
\hline 1 & Tidak Lengkap & 12 & 75 \\
\hline 2 & Lengkap & 4 & 25 \\
\hline & Total & $\mathbf{1 6}$ & $\mathbf{1 0 0}$ \\
\hline
\end{tabular}

Tabel diatas menunjukan bahwa distribusi ketidaklengkapan kode external cause pasien Orthopedi dari 16 responden yang telah diteliti, kode external cause yang tidak lengkap lebih banyak dari kode external cause yang lengkap. Kode external cause pasien orthopedi yang tidak lengkap sebanyak 12 berkas (75\%). Dan yang lengkap sebanyak 4 berkas (25\%). 
Analisis Bivariat

Tabel 9. Hubungan Faktor Umur dengan Ketidaklengkapan Kode External Cause Pasien Orthopedi

\begin{tabular}{|c|c|c|c|c|c|c|c|c|}
\hline \multirow{3}{*}{ No } & \multirow{3}{*}{ Umur } & \multicolumn{6}{|c|}{ Ketidaklengkapan Kode External Cause Pasien Orthopedi } & \multirow{3}{*}{$\boldsymbol{P}$} \\
\hline & & \multicolumn{2}{|c|}{ Lengkap } & \multicolumn{2}{|c|}{ Tidak Lengkap } & \multicolumn{2}{|c|}{ Total } & \\
\hline & & $\boldsymbol{F}$ & $\%$ & $\boldsymbol{F}$ & $\%$ & $F$ & $\%$ & \\
\hline 1 & 20-30 tahun & 7 & 43,7 & 5 & 31,2 & 12 & 75 & \multirow{4}{*}{1} \\
\hline 2 & $31-40$ tahun & 1 & 6,2 & 1 & 6,2 & 2 & 12,5 & \\
\hline 3 & $41-50$ tahun & 1 & 6,2 & 1 & 6,2 & 2 & 12,5 & \\
\hline & Total & 9 & 56,1 & 7 & 43,6 & 16 & 100 & \\
\hline
\end{tabular}

Tabel diatas menunjukan hasil uji artinya tidak ada hubungan antara umur statistik tentang pengaruh umur petugas rekam medis dengan ketidaklengkapan kode external cause pasien orthopedi. Diperoleh $\mathrm{p}=1>0.05$ sehingga Ho diterima petugas rekam medis dengan ketidaklengkapan kode external cause pasien orthopedi di RSUP.H. Adam Malik.

Tabel 10. Hubungan Faktor Jenis Kelamin dengan Ketidaklengkapan Kode External Cause Pasien Orthopedi di RSUP.H.Adam Malik

\begin{tabular}{|c|c|c|c|c|c|c|c|c|}
\hline \multirow{3}{*}{ No } & \multirow{3}{*}{ Jenis Kelamin } & \multicolumn{6}{|c|}{ Ketidaklengkapan Kode External Cause Pasien Orthopedi } & \multirow[t]{3}{*}{$\boldsymbol{P}$} \\
\hline & & \multicolumn{2}{|c|}{ Lengkap } & \multicolumn{2}{|c|}{ Tidak Lengkap } & \multicolumn{2}{|c|}{ Total } & \\
\hline & & $\boldsymbol{F}$ & $\%$ & $F$ & $\%$ & $F$ & $\%$ & \\
\hline 1 & Laki-laki & 2 & 12,5 & 2 & 12,5 & 4 & 25 & \multirow{3}{*}{1} \\
\hline 2 & Perempuan & 7 & 43,7 & 5 & 31,2 & 12 & 75 & \\
\hline & Total & 9 & 56,2 & 7 & 43,7 & 16 & 100 & \\
\hline
\end{tabular}

Tabel diatas menunjukan hasil uji statistik tentang pengaruh jenis kelamin petugas rekam medis dengan ketidaklengkapan kode external cause pasien orthopedi. Diperoleh $\mathrm{p}=1>0,05$ sehingga Ho diterima artinya tidak ada hubungan antara jenis kelamin petugas rekam medis dengan ketidaklengkapan kode external cause pasien orthopedi di RSUP.H. Adam Malik.

Tabel 11. Hubungan Faktor Pendidikan dengan Ketidaklengkapan Kode External Cause Pasien Orthopedi di RSUP.H. Adam Malik

\begin{tabular}{|c|c|c|c|c|c|c|c|c|}
\hline \multirow{3}{*}{ No } & \multirow{3}{*}{ Pendidikan } & \multicolumn{6}{|c|}{ Ketidaklengkapan Kode External Cause Pasien Orthopedi } & \multirow[t]{3}{*}{$\boldsymbol{P}$} \\
\hline & & \multicolumn{2}{|c|}{ Lengkap } & \multicolumn{2}{|c|}{ Tidak Lengkap } & \multicolumn{2}{|c|}{ Total } & \\
\hline & & $\boldsymbol{F}$ & $\%$ & $\boldsymbol{F}$ & $\%$ & $\boldsymbol{F}$ & $\%$ & \\
\hline 1 & D3 RMIK & 6 & 37,5 & 7 & 43,7 & 13 & 81,2 & \multirow{4}{*}{0,475} \\
\hline 2 & D3 non RMIK & 1 & 6,3 & 0 & 0 & 1 & 6,3 & \\
\hline 3 & S1 RMIK & 2 & 12,5 & 0 & 0 & 2 & 12,5 & \\
\hline & Total & 9 & 56,2 & 7 & 43,7 & 16 & 100 & \\
\hline
\end{tabular}

Tabel diatas menunjukkan hasil uji $\mathrm{p}=0,475>0,05$ sehingga Ho diterima artinya statistik tentang pengaruh pendidikan tidak ada hubungan antara pendidikan petugas rekam medis dengan petugas rekam medis dengan ketidaklengkapan kode external cause ketidaklengkapan kode external cause 0,475pasien orthopedi. Diperoleh pasien orthopedi di RSUP.H. Adam Malik.

Tabel 12. Hubungan Faktor Pengalaman Kerja dengan Ketidaklengkapan Kode External Cause Pasien Orthopedi di RSUP.H. Adam Malik

\begin{tabular}{|c|c|c|c|c|c|c|c|c|}
\hline \multirow[t]{3}{*}{ No } & \multirow{3}{*}{$\begin{array}{c}\text { Pengalaman } \\
\text { Kerja }\end{array}$} & \multicolumn{6}{|c|}{ Ketidaklengkapan Kode External Cause Pasien Orthopedi } & $\boldsymbol{P}$ \\
\hline & & \multicolumn{2}{|c|}{ Lengkap } & \multicolumn{2}{|c|}{ Tidak Lengkap } & \multicolumn{2}{|c|}{ Total } & \multirow{5}{*}{0,017} \\
\hline & & $\boldsymbol{F}$ & $\%$ & $F$ & $\%$ & $\boldsymbol{F}$ & \multirow{2}{*}{$\frac{\%}{25}$} & \\
\hline \multirow{2}{*}{$\begin{array}{l}1 \\
2 \\
\end{array}$} & \multirow{2}{*}{$\begin{array}{l}<1-3 \text { tahun } \\
<4-6 \text { tahun }\end{array}$} & 3 & 18,7 & 1 & 6,2 & 4 & & \\
\hline & & 1 & 6,2 & 6 & 37,5 & 7 & 43,7 & \\
\hline$\frac{2}{3}$ & $<7-10$ tahun & 4 & 25 & 0 & 0 & 4 & 25 & \\
\hline
\end{tabular}




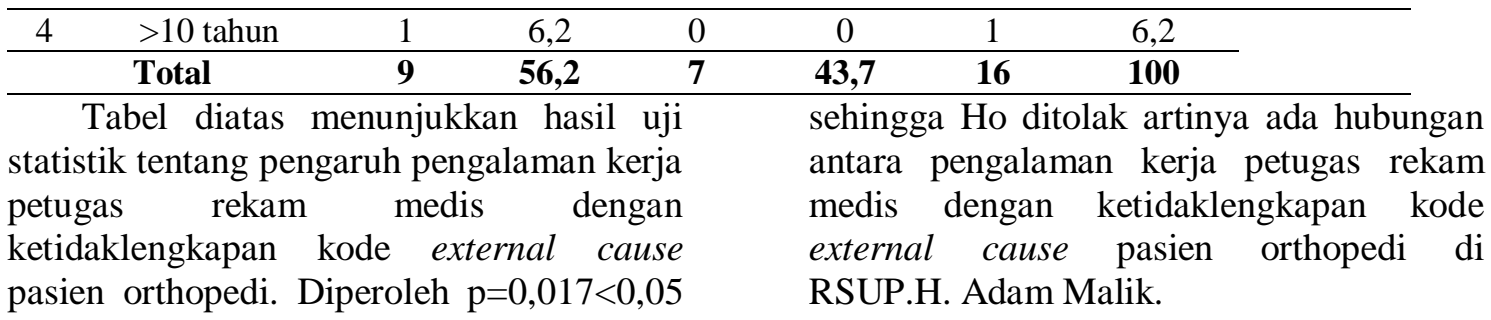

Tabel 13. Hubungan Faktor Pelatihan Koding Dengan Ketidaklengkapan Kode External Cause Pasien Orthopedi

\begin{tabular}{|c|c|c|c|c|c|c|c|c|}
\hline \multirow{3}{*}{ No. } & \multirow{3}{*}{ Pelatihan } & \multicolumn{6}{|c|}{ Ketidaklengkapan Kode External Cause Pasien Orthopedi } & \multirow[t]{3}{*}{$\boldsymbol{P}$} \\
\hline & & \multicolumn{2}{|c|}{ Lengkap } & \multicolumn{2}{|c|}{ Tidak Lengkap } & \multicolumn{2}{|c|}{ Total } & \\
\hline & & $\boldsymbol{F}$ & $\%$ & $F$ & $\%$ & $\boldsymbol{F}$ & $\%$ & \\
\hline 1. & Ada & 7 & 43,7 & 6 & 37,5 & 13 & 81,2 & \multirow{3}{*}{1} \\
\hline 2. & Tidak Ada & 2 & 12,5 & 1 & 6,2 & 3 & 18,8 & \\
\hline & Total & 9 & 56,2 & 7 & 43,7 & 16 & 100 & \\
\hline
\end{tabular}

Tabel diatas menunjukkan hasil uji artinya tidak ada hubungan antara pelatihan statistik tentang pengaruh pelatihan petugas petugas rekam medis dengan rekam medis dengan ketidaklengkapan ketidaklengkapan kode external cause kode external cause pasien orthopedi. pasien orthopedi di RSUP.H. Adam Malik.

Diperoleh $\mathrm{p}=1>0,05$ sehingga Ho diterima

Tabel 14. Hubungan Faktor Pengetahuan Dengan Ketidaklengkapan Kode External Cause Pasien Orthopedi

\begin{tabular}{|c|c|c|c|c|c|c|c|c|}
\hline \multirow[t]{3}{*}{ No } & \multirow[t]{3}{*}{ Pengetahuan } & \multicolumn{6}{|c|}{ Ketidaklengkapan Kode External Cause Pasien Orthopedi } & $\boldsymbol{P}$ \\
\hline & & \multicolumn{2}{|c|}{ Lengkap } & \multicolumn{2}{|c|}{ Tidak Lengkap } & \multicolumn{2}{|c|}{ Total } & \multirow{5}{*}{$\mathbf{0 , 0 0 0}$} \\
\hline & & $F$ & $\%$ & $F$ & $\%$ & $F$ & $\%$ & \\
\hline 1 & Baik & 9 & 56,3 & 0 & 0 & 9 & 56,3 & \\
\hline 2 & Cukup & 0 & 0 & 7 & 43,7 & 7 & 43,7 & \\
\hline & Total & 9 & 56,3 & 7 & 43,7 & 16 & 100 & \\
\hline
\end{tabular}

Tabel diatas menunjukkan hasil uji sehingga Ho ditolak artinya ada hubungan statistik tentang pengaruh pengetahuan petugas rekam medis dengan ketidaklengkapan kode external cause pasien orthopedic. Diperoleh $\mathrm{p}=0,000<0,05$ antara pengetahuan petugas rekam medis dengan ketidaklengkapan kode external cause pasien orthopedi di RSUP.H. Adam Malik.

Tabel 15. Hubungan Faktor Sikap Dengan Ketidaklengkapan Kode External Cause Pasien Orthopedi

\begin{tabular}{|c|c|c|c|c|c|c|c|c|}
\hline \multirow[t]{3}{*}{ No } & \multirow[t]{3}{*}{ Sikap } & \multicolumn{6}{|c|}{ Ketidaklengkapan Kode External Cause Pasien Orthopedi } & $\boldsymbol{P}$ \\
\hline & & \multicolumn{2}{|c|}{ Lengkap } & \multicolumn{2}{|c|}{ Tidak Lengkap } & \multicolumn{2}{|c|}{ Total } & \multirow{5}{*}{$\mathbf{0 , 0 1 1}$} \\
\hline & & $\boldsymbol{F}$ & $\%$ & $\boldsymbol{F}$ & $\%$ & $\boldsymbol{F}$ & $\%$ & \\
\hline 1 & Baik & 6 & 37,5 & 0 & 0 & 9 & 56,3 & \\
\hline 2 & Cukup & 3 & 18,7 & 7 & 43,7 & 7 & 43,7 & \\
\hline & Total & 9 & $\mathbf{5 6 , 2}$ & 7 & 43,7 & 16 & 100 & \\
\hline
\end{tabular}

Tabel diatas menunjukkan hasil uji statistik tentang pengaruh sikap petugas rekam medis dengan ketidaklengkapan kode external cause pasien orthopedi. Diperoleh $\mathrm{p}=0,011<0,05$ sehingga Ho ditolak artinya ada hubungan antara sikap petugas rekam medis dengan ketidaklengkapan kode external cause pasien orthopedi di RSUP.H. Adam Malik.

\section{PEMBAHASAN}

Hubungan Faktor Pengalaman Kerja Dengan Ketidaklengkapan Kode 


\section{External Cause Pasien Orthopedi di RSUP.H. Adam Malik.}

Dari hasil penelitian berdasarkan distribusi pengalaman petugas rekam medis dari 16 responden yang telah diteliti, petugas rekam medis dengan pengalaman kerja 4-6 tahun lebih banyak yaitu sebanyak 8 responden $(50 \%)$. Petugas rekam medis dengan pengalaman kerja $<7-10$ tahun sebanyak 3 responden $(18,8 \%)$. Sedangkan jika dilihat dari hubungan pengalaman kerja petugas rekam medis dengan ketidaklengkapan kode external cause pasien orthopedi. Diperoleh $\mathrm{p}=0,017<0,05$ sehingga Ho ditolak artinya ada hubungan antara pengalaman kerja petugas rekam medis dengan ketidaklengkapan kode external cause pasien orthopedi di RSUP.H. Adam Malik.

\section{Hubungan Faktor Pengetahuan Dengan Ketidaklengkapan Kode External Cause Pasien Orthopedi di RSUP.H. Adam Malik}

Dari hasil penelitian berdasarkan distribusi pengetahuan petugas rekam medis dari 16 responden yang diteliti, petugas rekam medis yang berpengetahuan baik lebih banyak dari petugas rekam medis yang berpengetahuan cukup. Petugas rekam medis yang berpengetahuan baik sebanyak 10 responden $(62,5 \%)$, dan petugas yang berpengetahuan cukup sebanyak 6 responden $(37,5)$. Sedangkan jika dilihat dari hubungan pengetahuan petugas rekam medis dengan ketidaklengkapan kode external cause pasien orthopedic. Diperoleh $\mathrm{p}=0,000<0,05$ sehingga Ho ditolak artinya ada hubungan antara pengetahuan petugas rekam medis dengan ketidaklengkapan kode external cause pasien orthopedi di RSUP.H. Adam Malik.

\section{Hubungan Faktor Sikap Dengan Ketidaklengkapan Kode External Cause Pasien Orthopedi di RSUP.H. Adam Malik}

Dari hasil penelitian berdasarkan distribusi sikap petugas rekam medis dari 16 responden yang telah diteliti, petugas rekam medis yang bersikap cukup lebih banyak dari petugas yang bersikap baik.
Petugas rekam medis yang bersikap cukup sebanyak 10 responden $(31,3 \%)$, dan petugas yang bersikap baik sebanyak 5 responden $(6,3 \%)$. Sedangkan jika dilihat dari hubungan sikap petugas rekam medis dengan ketidaklengkapan kode external cause pasien orthopedi. Diperoleh $\mathrm{p}=0,011<0,05$ sehingga Ho ditolak artinya ada hubungan antara sikap petugas rekam medis dengan ketidaklengkapan kode external cause pasien orthopedi di RSUP.H. Adam Malik.

\section{KESIMPULAN}

Dari hasil penelitian yang berjudul "Analisis Faktor Yang Mempengaruhi Ketidaklengkapan Kode External Cause Pasien Orthopedi Pada Dokumen Rekam Medis Rawat Inap di RSUP.H. Adam Malik Tahun 2018" dapat disimpulkan bahwa ada hubungan antara pengalaman kerja, pengetahuan dan sikap petugas rekam medis dengan ketidaklengkapan kode external cause pasien orthopedic di Rumah Sakit Umum Pusat Haji Adam Malik.

\section{SARAN}

Saran peneliti dalam penelitian ini adalah bagi instansi rumah sakit agar memberikan evaluasi skala berkala tentang kode external cause

\section{DAFTAR PUSTAKA}

Depkes RI Dirjen Pelayanan Medik. (2006). Pedoman Pengelolaan Rekam Medis Rumah Sakit Indonesia. Jakarta: Departemen Kesehatan Republik Indonesia Direktorat Jendral Pelayanan Medik.

Erkadius. (2012). Klasifikasi Statistik Internasional Mengenai Penyakit dan Masalah Kesehatan Terkait. Padang: Apikes Iris.

Firdaus, S.U. (2008). Rekam Medik Dalam Sorotan Hukum dan Etika. Surakarta: UNS-PRESS.

Hatta, G.R. (2012). Pedoman Manajemen Informasi Kesehatan di Sarana 
Pelayanan Kesehatan. Jakarta: Universitas Indonesia

Hatta, G.R. (2014). Pedoman Manajemen Informasi Kessehatan di Sarana Pelayanan Kesehatan. Jakarta: Universitas Indonesia.

International Classification of External Cause of Injury. (2017). ICECI.

Kementrian Kesehatan RI. (2010). Peraturan Menteri Kesehatan RI No. 340 tahun 2010. Klasifikasi Rumah Sakit. Jakarta: Kemenkes RI.

Notoadmodjo, S. (2012). Metodologi Penelitian Kesehatan. Jakarta: Rineka Cipta.

Pratiwi, K. (2016). Faktor-faktor yang Mempengaruhi Kelengkapan Kode External Cause pada DRM Rawat Inap di RSUD Brebes. KTI Universitas Dian Nuswantoro. Semarang: Universitas Dian Nuswantoro.

Riduwan. (2012). Skala Pengukuran Variabel-variabel Penelitian. Bandung: Alfabeta.
Rustiyanto, E. (2009). Etika Profesi Perekam Medis dan Informasi Kesehatan. Yogyakarta: Graha Ilmu.

Sartianingrum, M. (2014). Faktor -faktor yang Berhubungan Dengan Kelengkapan Informasi External Cause Pasien Instalasi Gawat Darurat Kasus Kecelakaan di Rumah Sakit Orthopedi Prof.Dr. R. Soeharso Surakarta. Thesis Universitas Muhammadiyah Surakarta.

Saryono, dkk. (2013). Metodologi Penelitian Kualitatif dan Kuantitatif Dalam Bidang Kesehatan. Yogyakarta: Nuha Medika.

Sulistyaningsih. (2011). Metodologi Penelitian Kebidanan KuantitatifKualitatif. Yogyakarta: Graha Ilmu.

Wawan, dkk. (2010). Teori dan Pengukuran Pengetahuan Sikap dan Perilaku Manusia. Yogyakarta: Nuha Medika.

World Health Organization. (2010). International Statistical Clasification of Diseases and Related Health Problems. USA: Geneva. 